\title{
Research article \\ Risk factors for breast cancer in Iran: a case-control study
}

Mandana Ebrahimi ${ }^{1}$, Mariam Vahdaninia ${ }^{1}$ and Ali Montazeri, ${ }^{1,2}$

1 Iranian Centre for Breast Cancer, Tehran, Iran

2Department of Public Health, University of Glasgow, Glasgow, Scotland

Correspondence: Dr Ali Montazeri, Director, Iranian Centre for Breast Cancer (ICBC), PO Box 13185-1488, Tehran, Iran. Tel: +98 21 6492431; fax: +98 21 6418036; e-mail: ali@jdcord.jd.ac.ir

Received: 12 January 2002

Breast Cancer Res 2002, 4:R10

Revisions requested: 20 March 2002

Revisions received: 7 May 2002

Accepted: 20 June 2002

Published: 9 July 2002

(C) 2002 Ebrahimi et al., licensee BioMed Central Ltd

(Print ISSN 1465-5411; Online ISSN 1465-542X)

\begin{abstract}
Background: Iranian breast cancer patients are relatively younger than their Western counterparts. The objective of the present study was to investigate risk factors for breast cancer in Iranian women. Method: A case-control study was conducted from April 1997 to April 1998 in Tehran, Iran. Demographical data and risk factor related information were collected using a short structured questionnaire. Odds ratios (ORs) and 95\% confidence intervals (Cls) were derived from logistic regression analysis.

Results: In all, 286 women with breast cancer and 249 control women were interviewed. In multivariate analysis, only marital status (never married: OR $4.24,95 \% \mathrm{Cl} 1.70-10.57[P=0.002]$; widowed/divorced: $\mathrm{OR} 1.71,95 \% \mathrm{Cl} 1.05-2.68[P=0.03]$ ) and family history (positive family history of breast cancer: $\mathrm{OR} 2.95,95 \% \mathrm{Cl} 1.15-7.59[P=0.02]$ ) were associated with significantly increased risk for breast cancer.

Conclusion: The findings of the present study suggest that family history and marital status may have an impact on the incidence of breast cancer in Iranian women.
\end{abstract}

Keywords: breast cancer, case-control, Iran, risk factor

\section{Introduction}

Geographical variations in incidence and mortality rates of breast cancer suggest that the known risk factors for breast cancer may vary in different parts of the world and that environmental factors are of greater importance than genetic factors [1]. For instance, in Iran it has been shown that, even after adjusting for age, young women are at relatively higher risk for developing breast cancer than are their Western counterparts [2]. Thus, study of risk factors for breast cancer in Iranian women is important and might contribute to current knowledge on this important topic. The aim of the present study was to examine the relationship between reproductive and other risk factors for breast cancer in Iranian women.

\section{Method}

A case-control study was conducted from April 1997 to April 1998 (one complete calendar year) in Tehran, Iran. The cases were incident, newly diagnosed breast cancer patients living in Tehran, and they were entered into the study if they had a confirmed pathological breast cancer diagnosis and were admitted to the Imam University Hospital (a large teaching and general hospital in the central district of Tehran) for breast surgery. The control women were recruited from female patients living in Tehran without any history of breast problems or neoplastic disease admitted to the same hospital for a wide spectrum of general surgical procedures. Women with hysterectomy and artificial menopause were excluded from the study.

$\mathrm{Cl}=$ confidence interval; $\mathrm{OR}=$ odds ratio. 
Although the hospital does not have an ethics committee, in addition to a written permission from hospital authorities, verbal consent was obtained from all participants. All women were interviewed by one investigator (MV).

Demographical and risk factor data were collected using a short structured questionnaire, including information on age, educational level, marital status, family history of breast cancer (first-degree relatives), age at menarche, parity, oral contraceptive use, age at first and last full-term pregnancy, menopausal status, and age at menopause. Women were classified as menopausal if they had not menstruated during the 6 months before the date of data collection. A full-term pregnancy was a pregnancy lasting 8 months or longer.

Univariate logistic regression analysis was performed to calculate odds ratios (ORs) and to examine the predictive effect of each factor on risk for breast cancer. $P<0.05$ was considered statistically significant. Those risk factors that were significantly associated with breast cancer were entered into a forward selection multivariate logistic regression analysis.

\section{Results}

In all, 286 women with breast cancer (from the total of approximately 300 women who were newly diagnosed as having breast cancer during the study period) and 249 control women were interviewed. The mean \pm SD age of cases and controls was $47.5 \pm 12.5$ years (range 24-81 years) and $44.2 \pm 13.3$ years (range $23-80$ years), respectively. There were no significant differences between cases and controls with regard to age (except for the age group $\geq 60$ years), educational level, age at menarche, past oral contraceptive use, age at first and last fullterm pregnancy, and age at menopause.

The results of univariate logistic regression analysis are shown in Table 1. Compared with married women, never married women were at higher risk for breast cancer (OR $4.25,95 \%$ confidence interval [Cl] 1.71-10.57). Breast cancer risk was significantly greater in women with a family history of the disease (OR 2.87, 95\% Cl $1.13-7.30$ ) and in nulliparous women (OR $2.78,95 \% \mathrm{Cl}$ 1.45-5.35). However, other variables did not exhibit a significant association with breast cancer except for age 60 years or older (OR 1.87, 95\% Cl 1.13-3.10).

On multivariate analysis, in addition to those factors that were found to carry a significant association with breast cancer in the initial analysis, age was also included. This was done because, although the study was not an agematched case-control study, older age exhibited a significant association on univariate analysis. The final model indicated that only marital status (never married: OR 4.24, 95\% Cl 1.70-10.57 [ $P=0.002]$; widowed/divorced: OR
$1.71,95 \% \mathrm{Cl} 1.05-2.68[P=0.03])$ and family history of breast cancer (positive family history: OR $2.95,95 \% \mathrm{Cl}$ $1.15-7.59[P=0.02])$ were significantly associated with breast cancer, and that nulliparity and older age were not significant risk factors for breast cancer.

\section{Discussion}

Breast cancer patients in Iran are relatively young, and the findings presented here suggest that marital status and a positive family history of breast cancer are risk factors for breast cancer in Iran. This is in accordance with other research findings indicating that a positive family history of breast cancer is a strong risk factor for breast cancer at young age [3], although this has a comparatively small effect on the absolute lifetime incidence of and mortality from breast cancer [4]. However, with regard to the findings from the present study, one may argue that the relatively high proportion of young breast cancer cases in Iran is most likely due a to a young population structure and to a combination of high age at menarche and low age at first pregnancy, which are protective in later life. Evidence from the USA [5] also suggests that, in some Asian subgroups such as the Vietnamese, women diagnosed with breast cancer tend to be younger than those from other racial or ethnic groups, with half of the diagnoses occurring in women younger than 50 years; this needs further exploration.

The findings presented here show that never married women were at higher risk for breast cancer. In most studies single and nulliparous married women were found to have a similar increased risk for breast cancer as compared with parous women of the same age [6]. Thus, one may argue that marital status by itself is not a determining factor for increased or reduced breast cancer risk, and rather the main protective effect is from early first full-term pregnancy. However, in the present study no association with parity emerged when multivariate analysis was performed. Evidence suggests that there is an interaction between marital status and parity [7], supporting a 'dual effect' of parity on breast cancer risk with pregnancy. Studies have shown that interactions between age, family history of breast cancer and parity might exist [8]. In addition, studies have reported that nulliparity reduces risk for breast cancer at younger age and elevates risk in the elderly $[9,10]$.

The lack of significant associations between breast cancer and the other variables studied was unexpected. For example, studies have shown that past oral contraceptive use is associated with a somewhat higher OR among young women or women who have a family history of breast cancer [11,12]. However, although there were clear patterns in ORs for most variables (Table 1), we suspect that this lack of significant associations may be explained by the limited power of the present study to estimate risk. 


\begin{tabular}{|c|c|c|c|c|}
\hline \multirow[b]{2}{*}{ Parameter } & \multicolumn{2}{|c|}{ Number $(\%)^{*}$} & \multirow[b]{2}{*}{ OR $(95 \% \mathrm{Cl})$} & \multirow[b]{2}{*}{$P$} \\
\hline & Cases $(n=286)$ & Controls $(n=249)$ & & \\
\hline \multicolumn{5}{|l|}{ Age groups (years) } \\
\hline$\leq 39$ & $87(30.4)$ & $101(40.6)$ & 1.00 (ref.) & \\
\hline $40-49$ & $84(29.4)$ & 68 (27.3) & $1.43(0.93-2.20)$ & 0.10 \\
\hline $50-59$ & $57(19.9)$ & $44(17.7)$ & $1.50(0.92-2.45)$ & 0.10 \\
\hline$\geq 60$ & $58(20.3)$ & $36(14.5)$ & $1.87(1.13-3.10)$ & 0.02 \\
\hline Mean $\pm \mathrm{SD}$ & $47.5(12.8)$ & $44.2(13.2)$ & & \\
\hline Median (range) & $46.0(24-81)$ & $43.0(23-80)$ & & \\
\hline \multicolumn{5}{|l|}{ Educational level } \\
\hline Illiterate & $87(30.4)$ & $91(36.5)$ & 1.00 (ref.) & \\
\hline Primary & $113(39.5)$ & $100(40.2)$ & $1.18(0.79-1.76)$ & 0.41 \\
\hline Secondary & $60(21.0)$ & $42(16.9)$ & $1.49(0.91-2.44)$ & 0.11 \\
\hline University & $26(9.1)$ & $16(6.4)$ & $1.70(0.85-3.38)$ & 0.13 \\
\hline \multicolumn{5}{|l|}{ Marital status } \\
\hline Married & $205(71.7)$ & 209 (83.9) & 1.00 (ref.) & \\
\hline Widowed/divorced & $56(19.6)$ & $34(13.7)$ & $1.68(1.05-2.68)$ & 0.03 \\
\hline Never married & $25(8.7)$ & $6(2.4)$ & $4.25(1.71-10.57)$ & 0.002 \\
\hline \multicolumn{5}{|c|}{ Family history of breast cancer } \\
\hline No & $267(93.4)$ & $243(97.6)$ & 1.00 (ref.) & \\
\hline Yes & $19(6.6)$ & $6(2.4)$ & $2.87(1.13-7.30)$ & 0.03 \\
\hline \multicolumn{5}{|l|}{ Age at menarche (years) } \\
\hline$\leq 12$ & $72(25.2)$ & $62(24.9)$ & $1.20(0.74-1.95)$ & 0.47 \\
\hline 13 & $78(27.3)$ & $63(25.3)$ & $1.28(0.79-2.1)$ & 0.32 \\
\hline 14 & $74(25.9)$ & $60(24.1)$ & $1.27(0.78-2.1)$ & 0.33 \\
\hline$\geq 15$ & $62(21.7)$ & $64(25.7)$ & 1.00 (ref.) & \\
\hline Mean $\pm S D$ & $13.4(1.5)$ & $13.5(1.7)$ & & \\
\hline Median (range) & $13.0(9-18)$ & $13.0(9-19)$ & & \\
\hline \multicolumn{5}{|l|}{ Parity } \\
\hline Parous & $249(87.1)$ & $235(94.4)$ & 1.00 (ref.) & \\
\hline Nulliparous & $37(12.9)$ & $14(5.6)$ & $2.78(1.45-5.35)$ & 0.002 \\
\hline \multicolumn{5}{|c|}{ Age at first full term pregnancy (years) } \\
\hline$<20$ & $127(51.0)$ & $131(55.7)$ & 1.00 (ref.) & \\
\hline $20-24$ & $71(28.5)$ & 72 (30.6) & $1.02(0.68-1.53)$ & 0.93 \\
\hline $25-29$ & $39(15.7)$ & $27(11.5)$ & $1.49(0.86-2.58)$ & 0.15 \\
\hline$\geq 30$ & $12(4.8)$ & $5(2.1)$ & $2.47(0.84-7.22)$ & 0.10 \\
\hline Mean \pm SD & $20.5(5.2)$ & $19.4(4.3)$ & & \\
\hline Median (range) & $19.0(11-45)$ & $19.0(10-35)$ & & \\
\hline \multicolumn{5}{|c|}{ Age at last full term pregnancy (years) } \\
\hline$\leq 29$ & 82 (32.9) & $85(36.2)$ & 1.00 (ref.) & \\
\hline $30-34$ & $69(27.7)$ & $70(29.8)$ & $1.02(0.65-1.60)$ & 0.92 \\
\hline $35-39$ & $62(24.9)$ & $49(20.9)$ & $1.31(0.81-2.12)$ & 0.27 \\
\hline$\geq 40$ & $36(14.5)$ & $31(13.2)$ & $1.20(0.68-2.12)$ & 0.52 \\
\hline Mean \pm SD & $32.5(6.4)$ & $31.6(6.9)$ & & \\
\hline Median (range) & $32.0(17-49)$ & $32.0(15-51)$ & & \\
\hline \multicolumn{5}{|l|}{ Menopausal status } \\
\hline Premenopausal & $186(65.0)$ & $180(72.3)$ & 1.00 (ref.) & \\
\hline Postmenopasual & $100(35.0)$ & $69(27.7)$ & $1.40(0.97-2.03)$ & 0.07 \\
\hline \multicolumn{5}{|l|}{ Age at menopause (years) } \\
\hline$<50$ & $42(42)$ & $37(53.6)$ & 1.00 (ref.) & \\
\hline$\geq 50$ & $58(58)$ & $32(46.4)$ & $1.60(0.86-2.96)$ & 0.14 \\
\hline Mean \pm SD & $49.9(4.9)$ & $48.0(5.2)$ & & \\
\hline Median (range) & $50.0(36-70)$ & $48.0(36-60)$ & & \\
\hline \multicolumn{5}{|l|}{ Oral contraceptive use } \\
\hline No & $279(97.6)$ & $240(96.4)$ & 1.00 (ref.) & \\
\hline Yes & $7(2.4)$ & 9 (3.6) & $0.67(0.25-1.82)$ & 0.43 \\
\hline
\end{tabular}

*Unless otherwise stated. $\mathrm{Cl}$, confidence interval; OR, odds ratio. 
Finally, one should be aware of the limitations of the present study, including case and control ascertainment and representation. Although the results cannot be generalized, the findings suggest that the associations between some known risk factors for breast cancer may differ in Iran as compared with Western countries, and that familial breast cancer in young Iranian breast cancer patients deserves further investigation.

\section{Acknowledgements}

The authors wish to thank the anonymous referees of the Journal for their helpful comments on a previous version of the paper.

\section{References}

1. McPherson K, Steel CM, Dixon JM: Breast cancer-epidemiology, risk factors, and genetics. BMJ 2000, 321:624-628.

2. Harirchi I, Ebrahimi M, Zamani N, Jarvandi S, Montazeri A: Breast cancer in Iran: a review of $\mathbf{9 0 3}$ case records. Public Health 2000, 114:143-145.

3. Pharoah PDP, Day NE, Duffy S, Easton DF, Ponder BAJ: Family history and the risk of breast cancer: a systematic review and meta-analysis. Int J Cancer 1997, 71:800-809.

4. Collaborative Group on Hormonal Factors in Breast Cancer: Familial breast cancer: collaborative reanalysis of individual data from 52 epidemiological studies including 58209 women with breast cancer and 101986 women without the disease. Lancet 2001, 358:1389-1399.

5. Lin SS, Phan JC, Lin AY: Breast cancer characteristics of Vietnamese women in the Greater San Francisco Bay Area. West J Med 2002, 176:87-91.

6. Rosner B, Colditz GA, Willett WC: Reproductive risk factors in a prospective study of breast cancer: the Nurses' Health Study. Am J Epidemiol 1994, 139: 819-835.

7. McCredie M, Paul C, Skegg DCG, Williams S: Reproductive factors and breast cancer in New Zealand. Int J Cancer 1998, 76:182-188.

8. Andrieu N, Prevost T, Rohan TE, Luporsi E, Le MG, Gerber M, Zaridze DG, Lifanova Y, Renaud R, Lee HP, Duffy SW: Variation in the interaction between familial and reproductive factors on the risk of breast cancer according to age, menopausal status, and degree of familiality. Int J Epidemio/ 2000, 29:214223.

9. Lipworth I: Epidemiology of breast cancer. Eur J Cancer Prev 1995, 4:7-30.

10. Tavani A Gallus S, La Vecchia C, Negri E, Montella M, Dal Maso L, Franceschi S: Risk factors for breast cancer in women under 40 years. Eur J Cancer 1999, 35:1361-1367.

11. Ursin G, Ross RK, Sullivan-Halley J, Hanisch R, Henderson B, Bernstein L: Use of oral contraceptives and risk of breast cancer in young women. Breast Cancer Res Treat 1998, 50: 175-184.

12. Grabrick DM, Hartmann LC, Cerhan JR, Vierkant RA, Therneau TM, Vachon CM, Olson JE, Couch FJ, Anderson KE, Pankratz VS, Sellers TA: Risk of breast cancer with oral contraceptive use in women with a family history of breast cancer. JAMA 2000, 284:1791-1798. 